\title{
Self-care promotion program for people with heart failure
}

\author{
Sanela Aljija, Tamara Arh, Jasna Kovač, Urška Ugovšek \\ University of Ljubljana, Faculty of Health Sciences, Ljubljana, Slovenia \\ sanela.a94@gmail.com; arh.tamara1995@gmail.com; jasna.kovac24@gmail.com; ugovseku@gmail.com
}

\begin{abstract}
Introduction: Statistics show that heart failure is a major public health problem, and in the population that continues to remain, the disease will only increase. Self-care includes activities performed by the patient to maintain life, healthy functioning, and well-being. Self-care in heart failure can be defined as a decision-making process that influences measures that maintain physiological stability, facilitate the perception of symptoms and the response to them. Coping with heart failure is often complicated, because it involves a complex treatment regimen. Methods: A descriptive method of working with a review of Slovenian and foreign literature using the Cochrane Library, CINAHL, PubMed and MedNar. The Google Scholar web browser was also used to search the literature. We were looking for literature that was published from 2010 to 2020 , the focus was on more recent literature. Results: Preventive activities in self-care measures reduce direct and indirect health care expenditure, so hospitalization is increased due to the health-related quality of life of patients. With different coping strategies (selective denial, goal setting) patients with heart failure achieved a better clinical outcome. In the future, we can expect a big increase in the need for appropriate therapeutic tools and approaches, in connection with heart failure. Above all, the need for education, self-care control and therapy titration. Solutions that will allow patients with heart failure to be treated appropriately are needed. Discussion and conclusions: Heart failure is a medical condition with frequent hospitalizations, high mortality, and high treatment costs. It is extremely important to involve patients in health education programs that encourage them to take active care of their health, to acquire the necessary knowledge and skills, and to form a positive attitude and behavioural patterns for a healthy lifestyle. Only through the joint action of all stakeholders in the field of health, the
\end{abstract}


economy, the non-governmental sector and others can we achieve better

health for all of us.

Keywords: heart failure, health promotion, self-care, self-management

\section{Introduction}

Heart failure (HF) is a common cardiovascular disease associated with high morbidity, mortality, and hospital admission. Heart failure is a major public health problem, the incidence of which is increasing. Current treatment of a patient with HF requires a multidisciplinary approach and includes four areas of care related to biomedical care, psychosocial care, self-care or self-management, and palliative care. The disease requires daily self-care, which is a major part of successful disease management. Self-management and self-care in HF refer to how the individual is responsible for the active management of daily activities such as compliance and regular use of medications, weight monitoring, and lifestyle change. Many factors can affect a person's ability to independently manage $\mathrm{HF}$, these include the socioeconomic status of the patient, the level of health literacy, access to ongoing family support, educational interventions, and the care model in a given health system (Cui et al., 2019).

Self-care includes activities performed by the patient to maintain life, healthy functioning, and well-being. Koirala and colleagues (2020) believe that the ability to perform self-care activities can improve both self-sufficiency and self-care management. The goal of self-care in HF is to improve the health outcomes of patients and to maintain the symptoms of HF in order to avoid avoidable complications. Optimal self-care includes proper medication, adherence to dietary instructions and a healthy lifestyle, monitoring of symptoms, taking appropriate measures to manage symptoms, and regular collaboration with healthcare professionals. Through these activities and measures, self-care helps to reduce direct and indirect health care expenditure, reduces hospitalizations and increases the health-related quality of life of patients.

\section{Methods}

We used a descriptive method of work; a review of Slovenian and English literature was made. Data for were selected from May 2021 to June 2021. Literature was searched in the Cochrane Library, CINAHL, PubMed and MedNar databases using the following keywords: heart failure, self-management, heart failure AND education. The Google Scholar web browser was also used to search the literature. The age of literature was limited from 2010 to 2021, the emphasis was on more recent literature. Articles with full access to the text related to the topic of heart failure were included. The exclusion criteria were: articles that did not have a complete article structure, articles that did not relate to the topic. In addition, the relevance of the content was also a selection criterion. 21 articles were reviewed, of which 10 articles were excluded according to the exclusion criteria. Articles that were not in Slovene or English were also excluded. 
The collected literature is professionally, substantively and topically related to the title of the work.

\section{Results}

Coping with HF is complex, as it often involves a complex treatment regimen. Patients with HF should follow dietary and exercise recommendations and should actively engage with the health facility (Gu et al., 2020).

Statistics confirm SP as a major public health problem, and in the population that remains, the disease will only increase. Promoting self-care and disease management through improved education and follow-up of people with HF can reduce the possibility of hospital admission, improve patient outcomes, and reduce healthcare-related costs, which remains essential in this population (Hart et al., 2020). If patients do not follow self-care activities, such as taking therapy regularly or weighing regularly, the symptoms of HF can obviously worsen.

Between 2004 and 2012, Lainščak and colleagues (2019) in Slovenia recorded 2,430,748 hospitalizations due to illness, of which 158,303 (6\%) with HF. The final sample of hospitalizations included 156,859 hospitalizations with SP.

A recent review showed that drug compliance ranges between 20 and $58 \%$. Patients should be advised to always take medication, even when they are feeling well, as this is due to effective treatment. It is most effective for people with HF to prepare therapy at home in containers or tablets for the next day, so that they do not forget to take medication (Rabelo et al., 2007).

We will educate patients and their relatives about heart failure and empower them to perform self-care, such as: Education about their medications and how to manage heart failure, changing eating habits, improving strength and mobility, daily exercise, monitoring vital signs and symptoms of heart failure, management of aggravated symptoms, proper use of devices to monitor blood pressure, heart rate and weight. Indicators of health and well-being of patients: reduced symptoms of the disease (decompensation symptoms), blood pressure and pulse within normal limits (normotension and normocardia), improved well-being of an individual with HF, reduced fear of self-care activity.

The aim is to reduce the burden of cardiovascular diseases among the Slovenian population, because cardiovascular diseases represent an important public health problem. However, the participation of the population is important for the success of the program, as a key change is the lifestyle of the people.

\section{Discussion}

The goal is to create a motivational model for the implementation of self-care as a method to improve their own well-being and strengthen their health - emphasis on people with heart failure and their relatives, and sports opportunities for everyone else. The goal is to increase knowledge about heart failure, 
and about self-care in doing so. In addition, the aim is to increase cooperation between organizations and groups of individuals, and to increase the number of transmitters of information through promotional activities and influential people, thereby increasing the number of politicians who support the proposed policy changes. A program to promote self-care in people with heart failure would achieve a higher quality of life for elderly who face such problems.

The advantages of the project are, above all, urging the elderly population to better self-care heart failure activity. Through these activities and measures, self-care helps to reduce direct and indirect health care expenditure, reduces hospitalizations and increases the health-related quality of life.

Opportunities for active participation in various sports activities, learning about diets and a healthy diet, which is crucial in managing and reducing symptoms. Individuals have the opportunity to talk individually with experts in the field. The program offers empowerment to heart failure sufferers as well as their relatives or close people, and can also lead to improved health, well-being and, consequently, the quality of life of individuals with HF and their relatives.

\section{Conclusions}

Heart failure is a medical condition with frequent hospitalizations, high mortality, and high treatment costs. Due to better treatment of acute conditions in cardiology and the aging of the population, the prevalence of heart failure is increasing, which is the only condition in cardiology whose burden is increasing. Therefore, important health education programs that encourage individuals (individual approach) or groups of the population (group approach) to begin to actively care for their health, acquire the necessary knowledge and skills, and develop positive attitudes and behavioural patterns for a healthy lifestyle.

Only through the joint action of all stakeholders in the field of healthcare, the economy, the non-governmental sector and others can we achieve better health for all of us.

\section{References}

CUI, X., ZHOU, X., MA, L., SUN, T., BISHOP, L., GARDINER, F.W., WANG, L., (2019). A nurse-led structured education program improves self-management skills and reduces hospital readmissions in patients with chronic heart failure: a randomized and controlled trial in China. Rural and Remote Health 19(2): 1-8. doi: https://doi.org/10.22605/RRH5270

GU, J., YIN, Z.F., ZHANG, H.L., FAN, Y.Q., ZHANG, J.F., WANG, C.Q., (2020). Characteristics and outcomes of transitions among heart failure categories: a prospective observational cohort study. ESC Heart Fail 7(2): 61625. doi: 10.1002/ehf2.12619. 
HART, J., NUTT, R., (2020). Improving inpatient education and follow-up in patients with heart failure: a hospital-based quality improvement project. Nurs Econ 38(2): 74-85. Available at: https://mdsoar.org/handle/11603/10795 [9.5.2020]

HENNING, R.J., (2020). Diagnosis and treatment of heart failure with preserved left ventricular ejection fraction. World J Cardiol 12(1): 7-25. doi: 10.4330/wjc.v12.i1.7.

KAMATH, D.Y., BHUVANA, K.B., DHIRAJ, R.S., XAVIER, D., VARGHESE, K., SALAZAR, L.J., GRANGER, C.B. et al., (2020). Patient and caregiver reported facilitators of self-care among patients with chronic heart failure: report from a formative qualitative study. Wellcome Open Res 5(10): 1-16. doi: 10.12688/wellcomeopenres.15485.2.

KOIRALA, B., BUDHATHOKI, C., DENNISON-HIMMELFARB, C.R., BHATTARAI, P., DAVIDSON, P.M., 2020. The self-care of heart failure index: A psychometric study. J Clin Nurs 29(3-4): 645-652.

LAINŠČAK, M., OMERSA, D., SEDLAR, N., ANKER, S., FARKAŠLAINŠČAK, J., (2019). Heart failure prevalence in the general population: SOBOTA-HF study rationale and design. ESC Heart Failure, ISSN 2055-5822, 2019, vol. 6, iss., str. https://onlinelibrary.wiley.com/doi/epdf/10.1002/ehf2.12496, doi: 10.1002/ehf2.12496.

LAMBRECHT, A., HARDT, R., 2019. Herzinsuffizienz im Alter: Aktuelle Empfehlungen mit Blick auf die überarbeitete Nationale VersorgungsLeitlinie Chronische Herzinsuffizienz. Z Gerontol Geriatr 52(7): 701-712. Doi: 10.1007/s00391-019-01617-0.

MARTI, C.N., FONAROW, G.C., ANKER, S., YANCY, C., VADUGANATHAN, M., GREENE, S,. et al., 2019. Medication dosing for heart failure with reduced ejection fraction. Eur J Heart Fail 21(3): 286-96. doi: 10.1002/ejhf.1351.

RABElO, E.R., Aliti, G.B., DOMINGUES, F.B., RUSCHEL, K.B., BRUN, A.O., 2007. What to teach to patients with heart failure and why: the role of nurses in heart failure clinics. Rev. Latino-Am. Enfermagem 15(1): 165170. https://doi.org/10.159o/So104-11692007000100024.

SUN, J., ZHANG, Z.W., MA, Y.X., LIU, W., WANG, C.Y., 2019. Application of self-care based on full-course individualized health education in patients with chronic heart failure and its influencing factors. World J Clin Cases 7(16): 2165-2175. doi: 10.12998/wjcc.v7.i16.2165. 